\title{
STRUCTURAL SOLUTIONS TO PRODUCE LONG TIMBER VENEER BASED COMPO- SITE HOLLOW SECTIONS
}

\author{
Benoit P. Gilbert ${ }^{(1)}$, Ian D. Underhill( ${ }^{(1)}$, Dilum Fernando ${ }^{(2)}$, Henri Bailleres ${ }^{(3)}$ \\ (1) Griffith School of Engineering, Griffith University, Australia \\ (2) School of Civil Engineering, The University of Queensland, Australia \\ (3) Salisbury Research Facility, Department of Agriculture and Fisheries, Queensland Government, Australia \\ Corresponding author: b.gilbert@griffith.edu.au
}

\begin{abstract}
Veneer Based Composite (VBC) hollow sections are currently being developed in Australia as alternative products to sawn timber. However, due to the limited log length that peeling lathes can accommodate, solutions to manufacture long sections need to be investigated to create useable beams and columns. This paper experimentally assesses the bending capacity of three different concepts. Two concepts consist of manufacturing short sub-sections and connecting them together with (i) a sleeve inserted into the hollow-form and (ii) wrapping Fibre Reinforced Polymer (FRP) around the sub-sections at the connection. The third concept consists of manufacturing the sections in a continuous process, similar to LVL products. Three sets of four nominally identical circular hollow sections (1.2 m long, nominal $76.1 \mathrm{~mm}$ internal diameter and $15 \mathrm{~mm}$ wall thickness) were manufactured from Hoop pine (Araucaria cunninghamii) veneers. In each set, one section was used as the reference capacity, two sections were cut in half with the two halves being connected back together with either an aluminium sleeve or Glass Fibre Reinforced Polymer (GFRP). The last section had the veneers staggered and end joined, to mimic a continuous manufacturing process. Once cured the sections were then tested in four points bending. The sleeved sections were found to have the lowest bending capacity, while the GFRP and continuous sections reached more than $80 \%$ of the capacity of the reference sections. The latter two designs, therefore offer a potential solution for creating useable lengths of VBC hollow sections. Further research is required to refine and validate the design.
\end{abstract}




\section{INTRODUCTION}

Currently, within the Australian forestry sector, early to mid-rotation hardwood plantation logs have no applications and little to no commercial value [1]. Spindleless technology has demonstrated to recover up to $70 \%$ of these small diameter logs into veneers [2] and offers the possibility to use this resource for Veneer Based Composite (VBC) products. In this effort, VBC hollow sections are currently being developed [3] and are seen as a potential solution to meet a range of applications, offering new market opportunities. These novel sections have the advantage of having an efficient cross-sectional shapes and able to be manufactured in large cross-sectional sizes that are no longer available in sawn timber. The manufacturing process is detailed in [4] and utilises the natural tendency of the veneers to curl about one side, creating an efficient process for gluing them into halfshapes around an inner mandrel. The veneer grain is orientated in the same direction (along the longitudinal axis of the section). The two half-sections are then butt joined together to form a full section, as shown in Figure 1 (a) for circular hollow sections (CHS). The concept was tested in [3] and proved to be an efficient and structurally sound solution to Australia's current shortage of traditional solid hardwood utility poles [5]. With applications also extending to the building industry, the sustainability of the product was studied in [6]. Figure 1 (b) shows a $145 \mathrm{~mm}$ external diameter CHS manufactured from mid-rotation Gympie messmate (Eucalyptus cloeziana) plantation thinned logs.

However, due to the limited log length that peeling lathes can accommodate (up to $1.3 \mathrm{~m}$ logs for the spindleless lathe used in the research [2] and up to $2.6 \mathrm{~m}$ for production lathes), the profiles can only be manufactured in short lengths. Solutions to manufacture longer sections therefore need to be investigated to create useable beams and columns.

Various concepts have been proposed in the literature to manufacture long timber hollow sections. In Kyoto University, long LVL cylinders [7, 8] were manufactured from Japanese cedar (Cryptmeria japonica D. Don.) by (i) finger joining veneers to create long veneers, (ii) hot-pressing the veneers into LVL in the shape of $1 / 6$ cylinders with a high frequency heating system and (iii) 
joining six LVL sections to form a complete cylinder. Finger joining the veneers did not apparently affect the veneer strength for practical use. To avoid the cost of edge joining the 1/6 cylinders together, spirally cylindrical laminated veneer lumbers were subsequently developed and manufactured using a continuous process, with veneer strips wrapped around a mandrel in alternative clockwise and anticlockwise directions to form an interlocking pattern [9-11]. The distance between butt joined veneer strips was found to influence the strength of the product [10]. At the Technische Universität Dresden in Germany, fibre-reinforced moulded wooden tubes, manufactured by shaping densified timber boards [12, 13] and wrapping them with layers of Fibres Reinforced Polymer (FRP) at $+/-45^{\circ}$, are being investigated. Long sections are achieved by finger joining timber subsections together before applying the FRP. The strength of the connection between the sub-sections was not evaluated as failure of the tubes in bending tests occurred due to local deformations at the loading points [13]. Recently, connecting two lengths of moulded wooden tubes with a steel circular hollow sections, in which the wooden tubes are inserted into and glued to the steel, was investigated [14]. In New Zealand, logs that are machined externally to a constant diameter and have had their inner core removed are commercialised [15]. These logs are connected together by internal steel annular grooved sleeves. Tests showed that the connection is successfully able to transfer the compression load with failure occurring in the timber $[16,17]$. In China, strips of Paulownia wood were sandwiched between Glass Fibre Reinforced Polymer (GFRP) sheets [18] to manufacture 4 m long and $500 \mathrm{~mm}$ outer diameter circular hollow sections. When tested in compression, failure was initiated by local buckling of the GFRP.

Additionally, timber hollow tubes have been commercialised, such as (i) spirally wrapped veneers manufactured in a continuous process with a commercialised maximum thickness of $10 \mathrm{~mm}$, diameter of $100 \mathrm{~mm}$ and length of $6 \mathrm{~m}$ [19], (ii) glulam hollow poles with standard diameter between $150 \mathrm{~mm}$ and $300 \mathrm{~mm}$ and length of $12 \mathrm{~m}$ [20] and (iii) veneered tubes and rings with commercialised maximum diameter of $1100 \mathrm{~mm}$ and length of $620 \mathrm{~mm}$ [21]. 
This paper experimentally assesses the bending capacity, efficiency and suitability of three different manufacturing concepts designed to produce useable lengths of the circular hollow VBC sections investigated in [3] and presented in Figure 1. The capacity of each concept is reported and compared to the capacity of a reference VBC hollow section. In addition, the structural behaviour and merits of each concept are discussed. Where applicable, the bending strength of the concepts is compared to the prediction of the simple failure mechanism model developed in [3]. Improvements of the tested concepts are discussed. The most suitable concept to manufacture long VBC hollow products is suggested.

\section{PROPOSED CONCEPTS}

Three different concepts were identified to produce useable lengths of VBC circular hollow sections. Two concepts involve joining short sub-sections together and the final concept involve manufacturing the hollow forms in a continuous process, similar to LVL products and [7, 8]. The general principles and rationale behind these concepts are discussed hereafter in Sections 2.1 to 2.3. The overall different design parameters to be considered are also discussed in these Sections while the specific design parameters selected for the experimentally investigated concepts are presented later in Section 3.

\subsection{Concept 1: Sleeve}

The first manufacturing concept involves producing the hollow forms in short sections that are restricted in length by the width of the peeling lathe $(1.3 \mathrm{~m})$. These short sections are then connected together by inserting a sleeve into the hollow forms. To avoid stress concentration both the sleeve and the timber hollow form must deform together and therefore need to have similar bending stiffness. Furthermore, to maximise the capacity of the connection, the bending strength of the sleeve must be greater than or equal to the bending strength of the hollow form. 
In keeping the joining sleeve hidden within the structure, the design aesthetically takes on the appearance of a light continuous timber element mimicking that of a conventional beams and columns.

Several design parameters that are likely to influence the efficiency and cost of the connection need to be considered for this concept. They include, but are not restricted to (i) the length and material of the sleeve, (ii) the necessity to bond the sleeve to the timber and (ii) type of joining details between timber sub-sections.

The design parameters selected for the tested sections are detailed in Section 3. Improvement to the tested design is discussed in Section 7.1.

\subsection{Concept 2: FRP}

Similar to the first concept, the second concept also involves manufacturing the hollow forms in short lengths which are subsequently connected together. Unidirectional Fibre Reinforced Polymer (FRP) is then wrapped around the hollow forms with fibres parallel to the longitudinal axis to transfer the load at the connection.

FRP materials have been successfully used to repair and retrofit timber structures [22-26]. The use of FRPs in strengthening existing structures has been mainly due to its high strength to weight ratio and less cumbersome installation process. Due to the shape flexibility of FRPs, it can be easily wrapped around the current hollow forms. Previous studies have shown that, externally bonded FRPs can significantly enhance the flexural capacity and stiffness of timber beams [24, 25]. Use of the FRPs was shown to greatly enhance the strength and stiffness of weaker timber sections (e.g. knot regions) [22] and is a possible solution to connect VBC hollow form.

Increase in strength and stiffness of FRP reinforced timber specimens depends on the axial stiffness of the FRP laminates [22]. In addition, debonding failures (often observed in bonded joints) may also affect the strength of the bonded joint. In FRP-to-steel bonded joints, parameters such as type of adhesive, adhered surface quality, joint geometry, and bond length were shown to affect the 
bond strength [27-29]. A similar study on FRP-to-timber bond joints is yet to be conducted. Nevertheless, based on the existing studies on FRP-to-steel bonded joints, design parameters such as type of adhesive, joint geometry and bond length can be considered as critical parameters for FRP-totimber bonded joints. Therefore, in the current study, the above design parameters need to be considered for the FRP concept with the (i) type and thickness of the FRP material and (ii) the type of joining details between timber sub-sections.

The design parameters selected for the tested sections are detailed in Section 3. Improvement to the tested design is discussed in Section 7.2.

\subsection{Concept 3: Continuous manufacturing process}

The third concept consists of end joining the veneers and staggering the joints, in a similar process used to construct LVL products, allowing long continuous sections to be formed (as in [7, 8]). Veneers should be staggered so that in any cross-section, only one joint between veneers can be found and in only one half cross-section (Figure 1 (a)). For a simple butt joint between veneers, i.e. that does not transfer the load, the net cross-sectional $A_{\text {net }}$ is then given as,

$$
A_{\text {net }}=A_{\text {gross }} \frac{n_{p l y}-1 / 2}{n_{p l y}}
$$

where $A_{\text {gross }}$ is the gross sectional area and $n_{p l y}$ is the number of ply constituting the LVL. The greater the number of plies is, the less the reduction in cross-sectional area, therefore increasing the capacity of the hollow form. Contrary to the previous two concepts, this design has the advantage of being able to manufacture the hollow sections in a continuous operation. Rather than joining subsections together, this concept creates a more homogeneous hollow section that can be cut to any length. However, as the sections are long, the manufacturing process is more complex than for short sections. One needs to either develop a continuous manufacturing process or have large presses. For the former process, the speed of manufacturing would have to be synchronised with the open 
time of the adhesive. Moreover, varying the wall thickness of the sections with the length may be more challenging than for the previous two solutions.

Design parameters that need to be considered for this concept include (i) the number of ply required to maximise the capacity while minimising the production cost and (ii) type of veneers joining process. The design parameters considered in the tested sections are detailed in Section 3. Improvement to the tested design is discussed in Section 7.3.

\section{MANUFACTURING}

Visually A-graded (face veneer) Hoop pine (Araucaria cunninghamii) rotary peeled veneers, 2.5 $\mathrm{mm}$ thick, free of natural defects were delivered in sheets of $1.3 \mathrm{~m} \times 1.3 \mathrm{~m}$. The veneers were used to manufacture three sets of $1.2 \mathrm{~m}$ long circular hollow sections, with a nominal internal diameter of $76.1 \mathrm{~mm}$ and a wall thickness of $15 \mathrm{~mm}$ (6 ply). Each set was composed of four sections manufactured from the same veneer sheets, glued in the exact same order, to create nominally identical sections. Different veneer sheets were used for each layer constituting the half-sections in Figure 1 (a). The veneers were conditioned in the laboratory for at least a month at ambient temperature and humidity before gluing, and each half-section was also manufactured at ambient temperature and humidity using resorcinol formaldehyde structural adhesive. To form a complete hollow section, two half-sections were butt joined and bonded together with structural epoxy. To align the half sections, the glue-line incorporated No 20 biscuit joints. In total, per set:

- One section was cut in half and the two halves were connected back together with a $300 \mathrm{~mm}$ long, $76.1 \mathrm{~mm} \times 6.35 \mathrm{~mm}$ CHS aluminium sleeve, as shown in Figure 2 (a). The sleeve has a nominal bending stiffness of $5.91 \times 10^{10} \mathrm{~N} \cdot \mathrm{mm}^{2}$. This is equal to the nominal bending stiffness of $5.95 \times 10^{10} \mathrm{~N} \cdot \mathrm{mm}^{2}$ of the timber sections, assuming a Modulus of Elasticity (MOE) of $13 \mathrm{GPa}$ for the Hoop pine [30]. Using the simple failure mechanical model for the timber hollow sections developed in [3] (see also Section 6), the aluminium sleeve has a capacity about $30 \%$ higher than the timber sections. A dry butt joint, representing the most economical joint, was chosen be- 
tween the two half sections. Polyurethane adhesive was used to glue the sleeve to the timber. Strain gauges (5 mm gauge length) were glued on the tension and compression sides of the inside of the aluminium sleeve, as shown in Figure 2 (a). The first tested section (Set 2) encountered a low bending capacity with the timber section failing in tension perpendicular to the grain (see Section 4.3.2 for more details). To avoid this mode of failure and improve the performance of the connection, two $25 \mathrm{~mm}$ wide steel hose clamps were added to the connection before tested the second section (Set 1), as shown in Figure 2 (a). The efficiency of the clamps was somewhat limited and two additional clamps were added to the third tested section (Set 3), as shown in Figure 2 (a).

- One section was cut in half and the two halves were connected back together with 4 layers of $0.17 \mathrm{~mm}$ thick unidirectional GFRP (nominal Elastic modulus of $73 \mathrm{GPa}$ and tensile strength of 2,400 MPa from manufacturer data sheet [31]), glued with epoxy adhesive. The fibre of the GFRP was orientated in the longitudinal direction of the timber section and was $600 \mathrm{~mm}$ long, as shown in Figure 2 (b). Similar to the previous concept, a dry butt joint was chosen between the two half sections. To monitor the failure mode observed when testing the first GFRP section (Set 2), three strain gauges (30 mm gauge length) were glued on the GFRP for the second and third tested sections (Sets 1 and 3). One strain gauge was glued at the connection on the tension side and two strain gauges were glued on the compression side, one at the connection and one 150 $\mathrm{mm}$ from it, as shown in Figure 2 (b).

- One section was used to mimic the continuous manufacturing process. The veneers that formed each half-section were cut in two and butt joined back together with the joints being offset 100 $\mathrm{mm}$ from each other, as shown in Figure 2 (c). The position of the butt joined veneers between the two half-sections were offset $50 \mathrm{~mm}$ from each other.

- One section, the reference section, did not incorporate a joining system and was used to measure the full capacity of the tested timber sections. It represents the reference capacity for each concept. 
Whilst the ultimate goal of this research is to manufacture the sections using veneers peeled from early to mid-rotation hardwood plantation trees (as in [3]), the veneers recovered from this feed stock display large variations in mechanical properties due to natural defects and the presence of growth stresses linked to juvenile wood. Therefore, if this resource was used, the difference in stiffness and strength between investigated concepts would likely be influenced by both the variation in material properties and the efficiency of the concepts. As the aim of this paper is to solely investigate the efficiency of the three identified concepts relative to each other and to the reference sections, Hoop pine veneers, presented uniform mechanical properties, as such minimise the influence of the material properties on the results.

Additionally, to determine the mechanical properties of the timber sections, two $300 \mathrm{~mm} \times 500$ mm flat LVL panels were also manufactured for each half-section. The panels were manufactured from the same veneer sheets used to produce the half-sections and were glued in the exact same layering order.

Before testing, the sections and flat panels were conditioned indoor in a temperature controlled, for a minimum period of one month, until they reached equilibrium at an average measured ovendry moisture content of $13.4 \%$.

\section{BENDING TESTS}

\subsection{Test set-up}

Two steel jigs, each composed of four $110 \mathrm{~mm}$ long reinforced quarter tubes, were used to rigidly clamp each end of the sections. Each jig was then bolted to a steel Rectangular Hollow Section (RHS), to form a beam of length $L=2,110 \mathrm{~mm}$. Similar to the test set-up in [3] and to fully transfer the moment from the steel RHS to the timber sections with minimum stress concentration, at the connection with the steel jig, two part epoxy resin filled with hardwood veneers was poured (i) inside the timber hollow forms to avoid local crushing of the timber hollow forms and (ii) on the outside of the timber sections to match the inside diameter of the steel jig thus ensuring a tight fit be- 
tween the elements. Figure 3 shows the clamping arrangement and the overall test set-up is shown in Figure 4

The sections were then tested in four points bending in a $500 \mathrm{kN}$ MTS universal testing machine. The load was applied to the steel RHS, as shown in Figure 4, loading the timber hollow sections in pure bending. The tests were run in displacement control and reached failure in about 8 minutes. For all tests, the butt joints between two half-sections lied in the horizontal plane.

Up to five Linear Variable Displacement Transducers (LVDT) recorded the vertical displacement at the bottom fibre of the timber sections. The position of the LVDT is given in Figure 4 for each investigated concept.

\subsection{Measurements}

The applied moment $M$ to the timber section is calculated as,

$$
M=\frac{\left(F+F_{w}\right) L_{1}}{2}
$$

where $F$ is the total applied load, $F_{w}=0.92 \mathrm{kN}$ is the gravity load exerted by the steel RHS at the points of application of the load and $L_{1}=455 \mathrm{~mm}$ is the distance between the supports and the points of application of the load, as shown in Figure 4 (a).

For all sections, but the sleeved sections, the relative displacement $\delta$ of the sections is calculated from the recorded displacement $\delta_{1}, \delta_{4}$ and $\delta_{5}$ of LVDT number 1, 4 and 5 in Figure 4 (a), respectively, as,

$$
\delta=\delta_{1}-\frac{\delta_{4}+\delta_{5}}{2}
$$

For the sleeved sections, it was not possible to position a LVDT at the joint and the relative displacement $\delta$ of the section is calculated from the recorded displacement $\delta_{2}, \delta_{3}, \delta_{4}$ and $\delta_{5}$ of LVDT number 2, 3, 4 and 5 in Figure 4 (a), respectively, as,

$$
\delta=\frac{\delta_{2}+\delta_{3}}{2}-\frac{\delta_{4}+\delta_{5}}{2}
$$


The bending stiffness $E_{s} I_{s}$ (where $E_{s}$ is the MOE parallel to the grain of the timber and $I_{s}$ is the second moment of area) of the sections is calculated from the test stiffness $k_{t}$ of the momentdisplacement curve $(M-\delta)$ as,

$$
M=k_{t} \delta
$$

$k_{t}$ is estimated herein by performing a linear regression on the linear portion of the curve, between 1 $\mathrm{kN} . \mathrm{m}$ and $3.5 \mathrm{kN} . \mathrm{m}$. The bending stiffness $E_{s} I_{s}$ of the sections is then expressed as,

$$
E_{s} I_{s}=\frac{k_{t} d^{2}}{2}
$$

where $d$ is the distance between transducers as shown in Figure 4 (a).

\subsection{Test results}

\subsubsection{Reference sections}

Figure 5 plots the moment-displacement curve $(M-\delta)$ of the three reference sections. Figure 5 shows that the sections behave linearly until about 4 kN.m and failure occurred between $5.5 \mathrm{kN}$.m and $6.5 \mathrm{kN} . \mathrm{m}$. The actual moment capacity $M_{s}$ of each tested section is reported in Table 1 . The sections failed in a brittle manner with failure initiating in the tension zone and propagating through to the cross-section until complete rupture of the sections, as shown in Figure 6.

The bending stiffness $E_{s} I_{s}$ of the sections is reported in Table 2 for information. The second moment of area $I_{S}$ of the tested section, calculated from measured external diameter and wall-thickness, is also given in Table 2.

\subsubsection{Sleeved sections (Concept 1)}

Figure 7 plots the moment-displacement curves $(M-\delta)$ of the three sleeved sections (Concept 1$)$. The moment capacity $M_{s}$ of each sleeved section is reported in Table 1 , relatively to the associated reference sections.

When no steel clamps were attached to the section in Set 2 (see Figure 2 (a)), the section experienced a low bending capacity equal to $30 \%$ of the capacity of the reference section, as outlined in 
Table 1. Adding two or four steel clamps in Sets 1 and 3, respectively, increased the bending capacity to nearly $50 \%$ of the capacity of the associated reference section (48\% for Set 1 and $49 \%$ for Set 3, see Table 1). While the improvement is significant, the bending capacity for Sets 1 and 3 is still low.

Despite both the aluminium sleeve and the timber hollow section having similar bending stiffness, localised crushing still occurred in the timber when no steel clamps were added (Set 2). The timber section failed at the connection, in a brittle manner, in tension perpendicular to the grain (i.e. tangential to the tube circumference), as shown in Figure 8 (a). The two steel clamps added in Set 1, as shown in Figure 2 (a), were effective in preventing this mode of failure. Failure occurred then with (i) the connection opening up at the butt joint between sub-sections on the tension side and the timber failing in compression parallel to the grain at this location and (ii) the aluminium sleeve locally crushing the timber section in the tension zone at about 100-150 mm from the connection. Figure 8 (b) illustrates the failure mode for Set 1 . No brittle failure occurred for Set 1 but a rapid decrease in the applied moment can be observed in the post-failure behaviour of the connection in Figure 7.

The two additional steel clamps were added in the last tested section (Set 3) to prevent the aluminium sleeve locally crushing the timber away from the connection, as in Set 1. Consequently, failure mainly occurred in the timber in compression parallel to the grain at the connection, as illustrated in Figure 8 (c). While all sections started to behave non-linearly at about 1.5 kN.m, as illustrated in Figure 7, Set 3 structurally behaved differently to Sets 1 and 2. The non-linear portion of the moment-displacement curve for Sets 1 and 2 remains stiff until it reaches a maximum moment. On the other hand, Set 3 experienced a large non-linear behaviour with a low stiffness and a moment that continuously increased until the test was stopped at an applied moment of 2.87 kN.m. This corresponds to the roller support in Figure 4 reaching its maximum allowable displacement, leading to an axial load developing in the section.

In all tested sets, permanent deformation of the aluminium sleeve was not observed. 
Figure 9 plots the strain gauge readings on the aluminium sleeve for Sets 1 and 3. Due to software issues, readings were not recorded for Set 2. As the connection opened up on the tension side, the two timber sub-sections moved away from each other and the aluminium sleeve would therefore carry the entire tension load. On the compression side of the connection, the two timber subsections were pushed against each other and the compression load was therefore shared between the timber and the aluminium sleeve. This is reflected in Figure 9 with the aluminium deforming about twice as much on the tension side (therefore carrying twice more load) than on the compression side.

\subsubsection{FRP sections (Concept 2)}

Figure 10 plots the moment-displacement curves $(M-\delta)$ of the three sections wrapped with GFRP (Concept 2). The moment-displacement curve mainly remains linear until failure develops on the compression side in the GFRP at the butt joint between sub-sections, as shown in Figure 11. A brittle failure mode was observed with the applied moment suddenly dropping by 30\% to 50\%.

The moment capacity $M_{s}$ of each GFRP section is reported in Table 1, relative to the associated reference sections. On average, the capacity of the GFRP sections is high and is only 6\% less than the reference sections, with Set 1 even reaching a higher capacity than its reference section. This is likely due to unavoidable variability in the timber material, and therefore between sections within a set, despite all precautions taken and outlined in Section 3.

Figure 12 plots the strain gauge readings on the GFRP for Sets 1 and 3. The strain rates of Gauges 1 (compression side) and Gauge 3 (tension side) is similar (6.5\% and $23 \%$ difference between the two strain gauges for Sets 1 and 3, respectively), implying that the GFRP deformed similarly at the connection at both the tension and compression zones and therefore likely carried the full bending moment at the butt joint between sub-sections. A small gap between the two sub-sections must have developed when connecting them back together, and due to the high stiffness of the GFRP, the two timber sub-sections did not come in contact in the compression zone, as for the sleeved sections 
(Concept 1). Moreover, this gap likely triggered the GFRP compression failure shown in Figure 11, with the unsupported GFRP buckling and failing within the gap. Gauge 2, positioned $150 \mathrm{~mm}$ away from the connection, shows that the GFRP deformed about twice as less at this location than at the butt joint (Gauge 1), implying that both timber and GFRP are resisting the load away from the connection.

\subsubsection{Continuous manufacturing process (Concept 3)}

Figure 13 plots the moment-displacement curves $(M-\delta)$ of the three continuous sections (Concept 3). The moment-displacement curves are similar to the reference sections. The failure mode is also similar to the reference sections with a brittle rupture of the sections. The failure initiated at the butt joint between the two veneers on the extreme fibre of the tension side, as shown in Figure 14.

The moment capacity $M_{s}$ of each continuous section is reported in Table 1, relative to the associated reference sections. On average, the capacity of the continuous sections is lower than the FRP sections, but still high, and only $17 \%$ less than the reference sections. This compares to a reduction of $8.3 \%$ of the total gross cross-sectional area (Eq. (1)), but of $16.6 \%$ of the gross cross-sectional area in the tension zone only, where failure initiates.

\section{MATERIAL TESTING}

\subsection{Strength}

Tension and compression samples were cut from the flat panels of the half-sections undergoing tension and compression, respectively. For the tensions samples, six nominal $10 \mathrm{~mm}$ wide $\times 125$ mm long (gauge length) coupon (dog bone) samples were cut for each half-section. The samples are similar to the ones recommended in the ASTM D3500-14 [32], however with a longer gauge length. For the compression samples, the flat panels were cut in two, and reglued together with a Polyurethane structural adhesive to form $30 \mathrm{~mm}$ nominal thick panels. The panels were then further cut into four nominal $60 \mathrm{~mm}$ wide $\times 100 \mathrm{~mm}$ long samples per half-section. 
All samples were tested in a $500 \mathrm{kN}$ MTS universal testing machine, at similar strain rates to the ones experienced by the hollow sections. The tension samples were loaded following the recommendations in the ASTM D3500-14 [32] and only the samples failing in the gauge length are reported hereafter. The compression samples were loaded following the recommendations in the Australian-New Zealand standard AS/NZS 4357.2 [33]. Figure 15 illustrates the test set-ups.

The tensile $\sigma_{f \text {,tens }}$ and compressive $\sigma_{f, \text { comp }}$ strengths of the tension and compression samples, respectively, are reported in Table 3. The measured dimensions of the samples are used to calculate the strength in Table 3.

\subsection{Modulus of Elasticity (MOE)}

The MOE parallel to the grain $E_{L}$ of the half-sections was determined by applying the following two methods:

- Extensometers (50 mm gauge length) were attached to the compression samples, as shown in Figure 15 (a). Two extensometers, positioned on opposite faces, were used to avoid measuring the out-of-straightness deformation with the pure compression deformation. The MOE of each sample was calculated as the average of the MOE given by the two extensometers and measured by performing a linear regression on the linear portion of the stress-strain curves. Due to the brittle failure of the tension samples and the associated risk of damaging the extensometers, no extensometers were attached to the dog bone samples.

- Two nominal $20 \mathrm{~mm}$ wide $\times 400 \mathrm{~mm}$ long strips were cut from opposite edges of the flat panels for each half-section. The MOE was then measured using a non-destructive resonance method [34]. The strips were simply supported on rubber strips and impacted with a hammer. The natural frequency of the strip was recorded using a microphone and analysed using the software BING ${ }^{\circledR}$ (Beam Identification by Nondestructive Grading) [35]. 
Table 4 provides the average measured $\mathrm{MOE} E_{L}$ for all tested sections. The dynamic MOE (resonance method) displays is on average $8.7 \%$ greater than the static MOE (extensometers) due to the viscoelastic nature of wood [36, 37]

\section{SIMPLE FAILURE MECHANISM MODEL IN BENDING}

The simple failure mechanical model in bending for the timber hollow sections developed and detailed in [3] is verified herein for the reference and the continuous sections tested in pure bending (Section 4.3). The Euler-Bernoulli beam theory is used in the model, with plane sections remaining plane. The material anisotropy is not considered as stresses are assumed to solely occur parallel to the grain (pure bending). The model does not consider (i) the strength reduction due to local buckling of the sections and (ii) ovalisation (Brazier effect) of the cross-section in bending, and is therefore mainly valid for compact cross-sections. A perfect elastic-plastic material in compression parallel to the grain and an elastic material (linear) in tension is considered in the model. The model takes into account the shift in neutral axis to obtain the equilibrium between the tension and compression forces within a cross-section. Failure is assumed to be triggered by a brittle failure on the tension side of the section (typical failure mode of timber elements in bending). Specifically, failure is simply assumed herein to occur when the stress at the extreme fibre of the tension side reaches the average measured stress $\sigma_{f, t e n s}$, reported in Table 3. The MOE and strengths measured from material testing are used as input parameters. For the continuous section, only five veneers out of the six are assumed to resist the bending moment on the tension side of the section.

Using the mechanical properties (MOE, compressive and tensile strengths) measured in Table 3 and Table 4, and measured external diameter $D$ and wall-thickness of the sections as input parameters, the model moment capacity $M_{m}$ numerically calculated for each tested section in Sections 4.3.1 and 4.3.4 is reported in Table 1.. On average the model accurately estimates (within 6\%) the bending capacity of the sections. The maximum error is found for the continuous section in Set 2 and is equal to $15 \%$. The model therefore represents a promising and simple tool to accurately estimate the 
bending capacity of the sections from the material properties. Yet, improvement of the model is needed, outside the scope of this paper, to consider the length effect in timber [38] and more accurately define the failure criteria, as in $[39,40]$.

\section{DISCUSSION}

\subsection{Sleeved section (Concept 1)}

Despite being a simple concept, the capacity of the sleeved sections is too low when compared to the reference section. Therefore, this concept would only be practical if the connections are placed in low bending regions. Yet, as the length of the sub-sections is small (1.2 m) relative to a typical beam length (about 6 to $8 \mathrm{~m}$ ), connections are likely to be located in high bending regions and would therefore restrict the applications and limit the design. As failure does not solely occur at the butt joint between sub-sections, using a more robust joint at this location (such as a finger joint arrangement) is unlikely to improve the capacity of the connection. In view of the test results, the sleeve concept is unlikely to be a structurally viable solution in its current form to manufacture beams of usable lengths.

To improve the concept, unidirectional natural FRPs, that have close mechanical properties to timber and are suitable to be glued with structural adhesives commonly used in the timber industry, can be inserted between veneers along the tangential direction of the hollow forms. These FRPs would homogenously reinforce the timber perpendicular to the grain and may limit the failure modes observed when steel clamps were used. Further investigation is needed.

\subsection{FRP section (Concept 2)}

The capacity of the sections that were wrapped with GFRP at the connection proved to be close (94\%) to the capacity of the reference sections. As failure occurred in the GFRP in compression, which is likely due to a small gap between the two sub-sections, gluing the sub-sections together before applying GFRP is suggested. Gluing two sub-sections together can be done, either with a butt joint or finger joint (like in [13]). Such gluing will eliminate the gap between two sub-sections, 
thus eliminating/delaying the observed mode of failure. This will further increase the capacity of the sections until it reaches the capacity of the timber section without GFRP. Wrapping GFRP around two sub-sections to connect them together is therefore identified as a structurally viable solution to produce long beams and columns. More investigation is needed to characterise the appropriate type of joint between sub-sections and the amount of GFRP needed to match the capacity of the timber hollow sections.

\subsection{Continuous section (Concept 3)}

While less effective than the FRP sections, the continuous manufacturing also demonstrated the ability to reach a high capacity relative to the reference sections (83\%). As failure is triggered at the butt joint between the veneers, the capacity of the sections can be further improved by (i) scarf joining or crushed lapping the veneers [41] or (ii) reinforcing the butt joint with thin natural fibre meshes that can be glued with the sections and with the same adhesive. Alternatively, the number of ply can also be increased to further improve the capacity of the sections. While manufacturing continuous sections represents a structurally viable solution to produce useable beams and columns, more investigation is needed to determine the relative gain in capacity relative to the cost of joining the veneers.

\section{CONCLUSION}

This paper experimentally investigated three different concepts to manufacture useable beams and columns Veneer Based Composite hollow sections. Three sets of four nominally identical circular hollow sections were manufactured from high grade Hoop pine veneers. Per set, one section was used as the reference section and each concept was tested on the remaining three sections. The sections were tested in four points bending in a custom manufactured rig. Results showed that inserting a sleeve in the hollow form of similar stiffness and strength to the timber section is not a structurally viable solution, resulting in low bending capacity relative to the reference section (maximum of 50\%). However, wrapping FRP (GFRP in this study) around timber sub-sections to connect them 
together and manufacturing the sections in a continuous process, by staggering the veneers, represent structurally sound solutions that can be potentially used to produce long beams and columns. The latter two concepts reached bending capacity higher than $80 \%$ of the capacity of the reference sections. Suggestions to further improve the capacity of these concepts are also discussed in the paper.

\section{ACKNOWLEDGMENT}

The authors would like to thank the Australian Research Council for its financial contribution under project DE140100212. Mr Matthew Slade and Dr Dane Miller are also acknowledged for their valuable contribution in manufacturing the timber hollow sections. 


\section{REFERENCES}

[1] McGavin RL, Davies MP, Macgregor-Skinner J, Bailleres H, Armstrong M, Atyeo WJ, et al. Utilisation Potential and Market Opportunities for Plantation Hardwood Thinnings from Queensland and Northern New South Wales. Department of Primary Industries and Fisheries, Queensland Department; 2006.

[2] McGavin RL, Bailleres H, Lane F, Blackburn D, Vega M, Ozarska B. Veneer Recovery Analysis of Plantation Eucalypt Species Using Spindleless Lathe Technology. BioRessources. 2014; 9(1):613-27.

[3] Gilbert BP, Underhill ID, Bailleres H, El Hanandeh A, McGavin RL. Veneer Based Composite hollow utility poles manufactured from hardwood plantation thinned tress. Construction and Building Materials. 2014; 66:458-66.

[4] Underhill ID, Gilbert BP, Bailleres H, McGavin RL, Patterson D. Structural Veneer Based Composite products from hardwood thinning - Part I: Background and manufacturing. In: Aicher A, Reinhardt H-W, Garrecht H, editors. RILEM Conference "Materials and Joints in Timber Structures - Recent Advancement of Technology”. Stuttgart, Germany 2013. p. 577-88.

[5] Francis L, Norton J. Australian timber pole resources for energy networks. In: Department of Primary Industry and Fisheries QG, editor. Brisbane, Australia: Department of Primary Industry and Fisheries, Queensland Government; 2006.

[6] Lu H, El Hanandeh A. Life cycle assessment of ACQ-treated Veneer Based Composite (VBC) hollow utility poles from hardwood plantation mid-thinning. Sustainable Production and Consumption. 2016; (5):36-50.

[7] Sasaki H, Kawai S. Recent research and development work on wood composites in Japan. Wood Science and Technology. 1994; 28:241-8.

[8] Hara Y, Kawai S, Sasaki H. Manufacture and mechanical properties of cylindrical laminated veneer lumber. Japan Wood Research Society. 1994; 81:28-30.

[9] Hata T, Umemura K, Yamauchi H, Nakayama A, Kawai S, Sasaki H. Design and pilot production of a spiral-winder for the manufacture of cylindrical laminated veneer lumber. Journal of Wood Science. 2001; 47:115-23.

[10] Berard P, Yang P, Yamauchi H, Umemura K, Kawai S. Modeling of a cylindrical laminated veneer lumber I: mechanical properties of hinoki (Chamaecyparis obtusa) and the reliability of a nonlinear finite elements model of a four-point bending test. Journal of Wood Science. 2011:1-7.

[11] Berard P, Yang P, Yamauchi H, Umemura K, Kawai S. Modeling of a cylindrical laminated veneer lumber II: a nonlinear finite element model to improve the quality of the butt joint. Journal of Wood Science. 2011:1-7.

[12] Wehsener J, Werner T, Hartig J, Haller P. Advancements for the structural application of fiberreinforced moulded wooden tubes. In: Aicher S, Reinhardt H-W, Garrecht H, editors. RILEM Conference "Materials and Joints in Timber Structures - Recent Advancement of Technology”. Stuttgart, Germany 2013. p. 99-108.

[13] Haller P, Hartig J, Wehsener J. Application of moulded wooden tubes as structural elements. In: Salenikovich A, editor. 2014 World Conference on Timber Engineering. Quebec City, Canada 2014. p. Paper ABS684.

[14] Hahn B, Haller P. Adhesively bonded steel connectors for moulded wooden tubes in spatial truss structures. In: Eberhardsteiner J, Winter W, Fadai A, Pöll M, editors. 2016 World Conference on Timber Engineering. Vienna, Austria 2016. p. Electronic proceedings. 
[15] TTT Products Limited. TTT Multipoles - hollow poles for foundations (Brochure). Acessed on 21/01/2016, http://www.unilog.co.nz/uploads/TTT MultiPole\%20Brochure.pdf,

[16] Morris H, Batchelar M, Teh K. Full strength round timber pole connection using annular grooves. NZ Timber Design Journal. 2009; 17(2):13-9.

[17] Batchelar M. Innovative use of timber rounds in high performance structures. In: Quennevile P, editor. 2012 World Conference on Timber Engineering. Auckland, New-Zealand 2014. p. 557-63.

[18] Wang L, Liu W, Hui D. Compression strength of hollow sandwich columns with GFRP skins and a paulownia wood core. Composites Part B: Engineering. 2014; 60:495-506.

[19] Lignotube. LignoTUBE - the new semi-finished product for lightweight construction. 2017, http://lignotube.com/description/, Accessed on 01/02/2017

[20] Martinsons. Timber and glulam products for industrial manufacturing and modern construction. 2017, http://www.martinsons.se/Allm\%C3\%A4n/Filer/Travaror/travaror_eng.pdf, Accessed on 01/02/2017

[21] $\mathrm{K}+\mathrm{W}$ Formholztechnik GmbH. Rings and Tubes. 2017, http://www.formholz.de/produkte und loesungen/standardprodukte/ringe und roehren, Accessed on $01 / 02 / 2017$

[22] Fernando D, Frangi A, Kobel P. Behaviour of basalt fibre reinforced polymer strengthened timber laminates under tensile loading. Engineering Structures. 2016; (Accepted for publication).

[23] Fiorelli J, Dias AA. Analysis of the strength and stiffness of timber beams reinforced with carbon fiber and glass fiber. Materials Research. 2003; 6(2):193-202.

[24] Moulin JM, Pluvinage G, Jodin P. FGRG: Fibreglass reinforced glulam - a new composite. Wood Science and Technology 1990; 24(3):289-94.

[25] Raftery GM, Harte AM. Low-grade glued laminated timber reinforced with FRP plate. Composites Part B: Engineering. 2011; 42(4):724-35.

[26] Schober K-U, Harte AM, Kliger R, Jockwer R, Xu Q, Chen J-F. FRP reinforcement of timber structures. Construction and Building Materials. 2015; 97:106-18.

[27] Fernando D, Teng JG, Yu T, Zhao XL. Surface preparation of steel surface for adhesive bonding. ASCE Journal of Composites for Construction,. 2013; 17(6):04013012.

[28] Fernando D, Yu T, Teng JG, Zhao XL. CFRP strengthening of rectangular steel tubes subjected to end bearing loads: Effect of adhesive properties and finite element modelling. Thin-Walled Structures. 2009; 47(10):1020-8.

[29] Teng JG, Yu T, Fernando D. Strengthening of steel structures with fiber-reinforced polymer composites. Journal of Constructional Steel Research. 2012; 78:131-43.

[30] Kingston RST. The mechanical properties of Queensland grown hoop pine. South Melbourne, Australia: Commonwealth of Australia - Council for Scientific and Industrial Research - Division of Forest Products; 1947.

[31] Saint-Gobain Vetrotex. E, R and D glass properties - Technical data sheet. Herzogenrath, Germany: Saint-Gobain Vetrotex,; 2002.

[32] ASTM D3500-14. Standard Test Methods for Structural Panels in Tension. ASTM International, Pennsylvania, USA; 2014. 
[33] AS/NZS 4357.2. Structural laminated veneer lumber, Part 2: Determination of structural properties Test methods. Standards Australia, Sydney, Australia; 2006.

[34] Brancheriau L, Bailleres H. Natural vibration analysis of clear wooden beams: a theoretical review. Wood Science and Technology. 2002; 36:347-65.

[35] CIRAD. BING® (Beam Identification by Nondestructive Grading) software. 2012, https://www.picotech.com/library/application-note/non-destructive-testing-of-wood,

[36] Bruel and Kjaer. Measurement of the Complex Modulus of Elasticity: A Brief Survey. Bruel and Kjaer, Nærum, Danemark; 1982.

[37] Banks HT, Hu S, Kenz ZR. A Brief Review of Elasticity and Viscoelasticity for Solids. Advances in Applied Mathematics and Mechanics. 2011; 3(1):1-51.

[38] Isaksson T. Structural timber - Variability and statistical modelling (Chapter 4). In: Thelandersson S, Larsen HJ, editors. Timber Engineering. England: Wiley and Sons; 2003.

[39] Buchanan AH. Combined bending and axial loading in lumber. ASCE Journal of Structural Engineering. 1986; 112(12):2592-609.

[40] Buchanan AH. Bending Strength of Lumber. ASCE Journal of Structural Engineering. 1990; 116(5):1213-29.

[41] Lee JN, Tang RC, Kaiserlik JH. Edgewise static bending properties of yellow-poplar laminated veneer lumber: Effect of veneer-joint designs. Forest Products Journal. 1999; 49(7):64-70. 


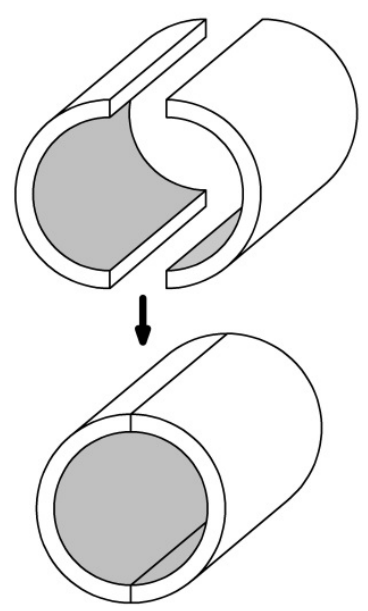

(a)

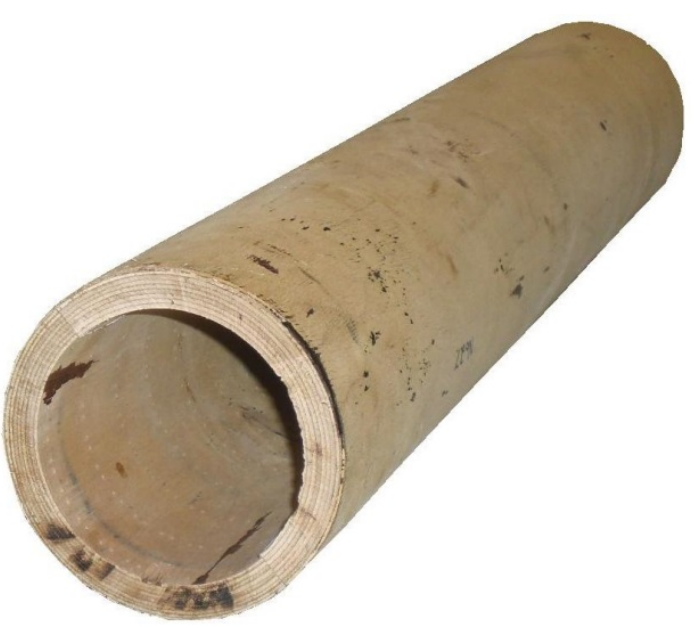

(b)

Figure 1: (a) half-sections butt joined and (b) $145 \mathrm{~mm}$ external diameter circular hollow section manufactured from Gympie messmate

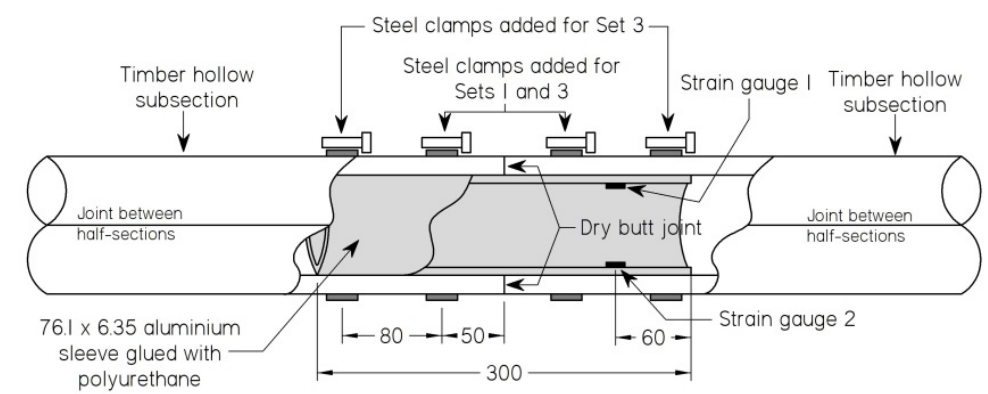

(a)

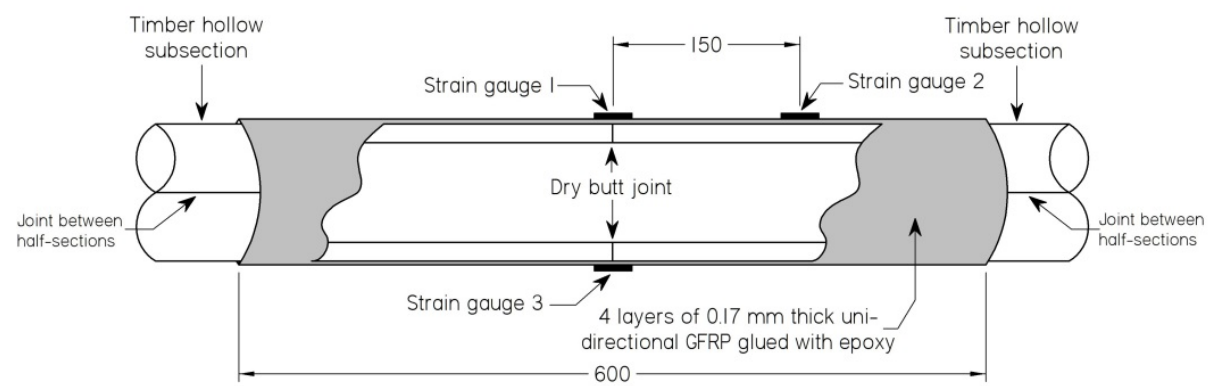

(b)

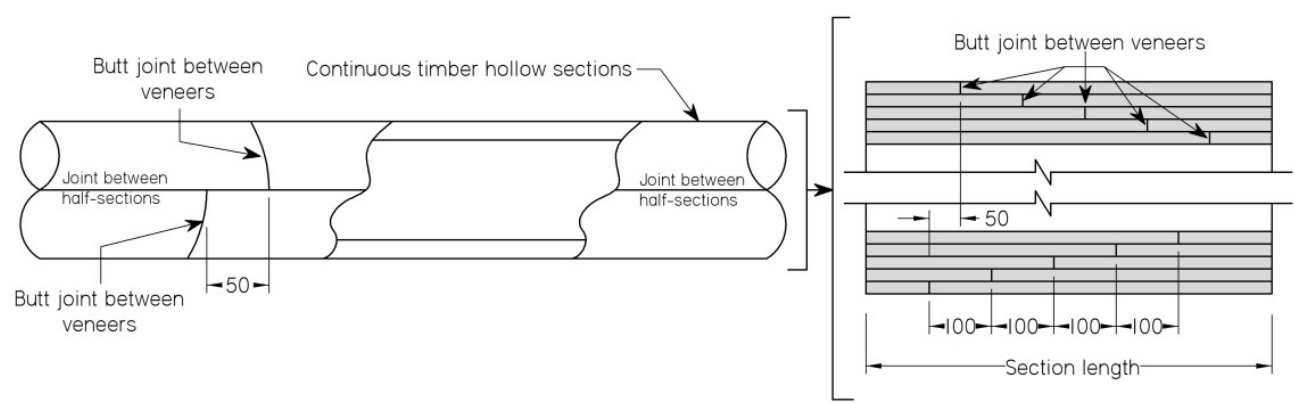

(c)

Figure 2: Manufactured (a) Sleeved section (Concept 1), (b) FRP section (Concept 2) and (c) Continuous section (Concept 3 ) 


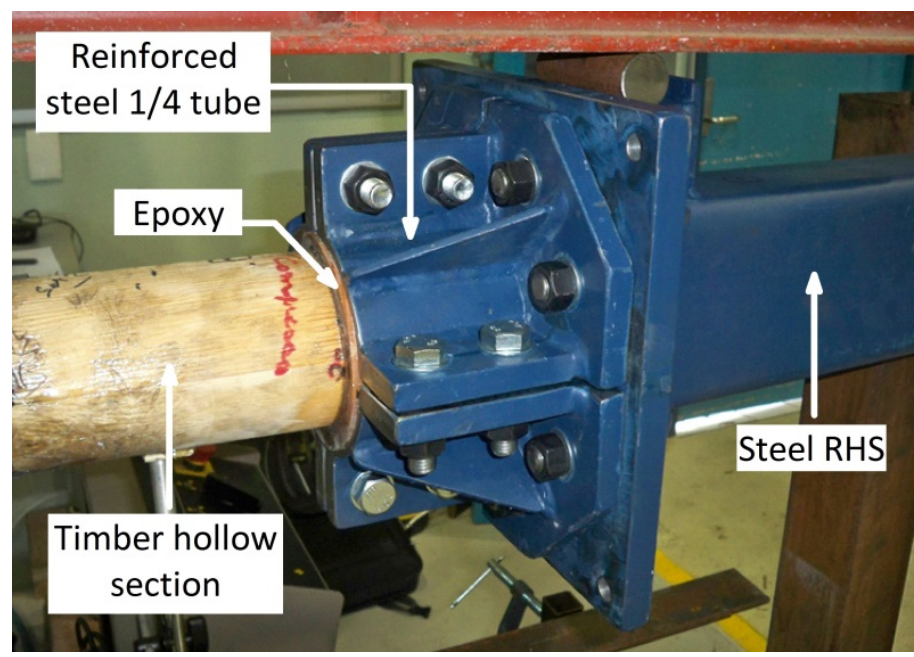

Figure 3: Clamping arrangement to connect the sections to the testing rig 


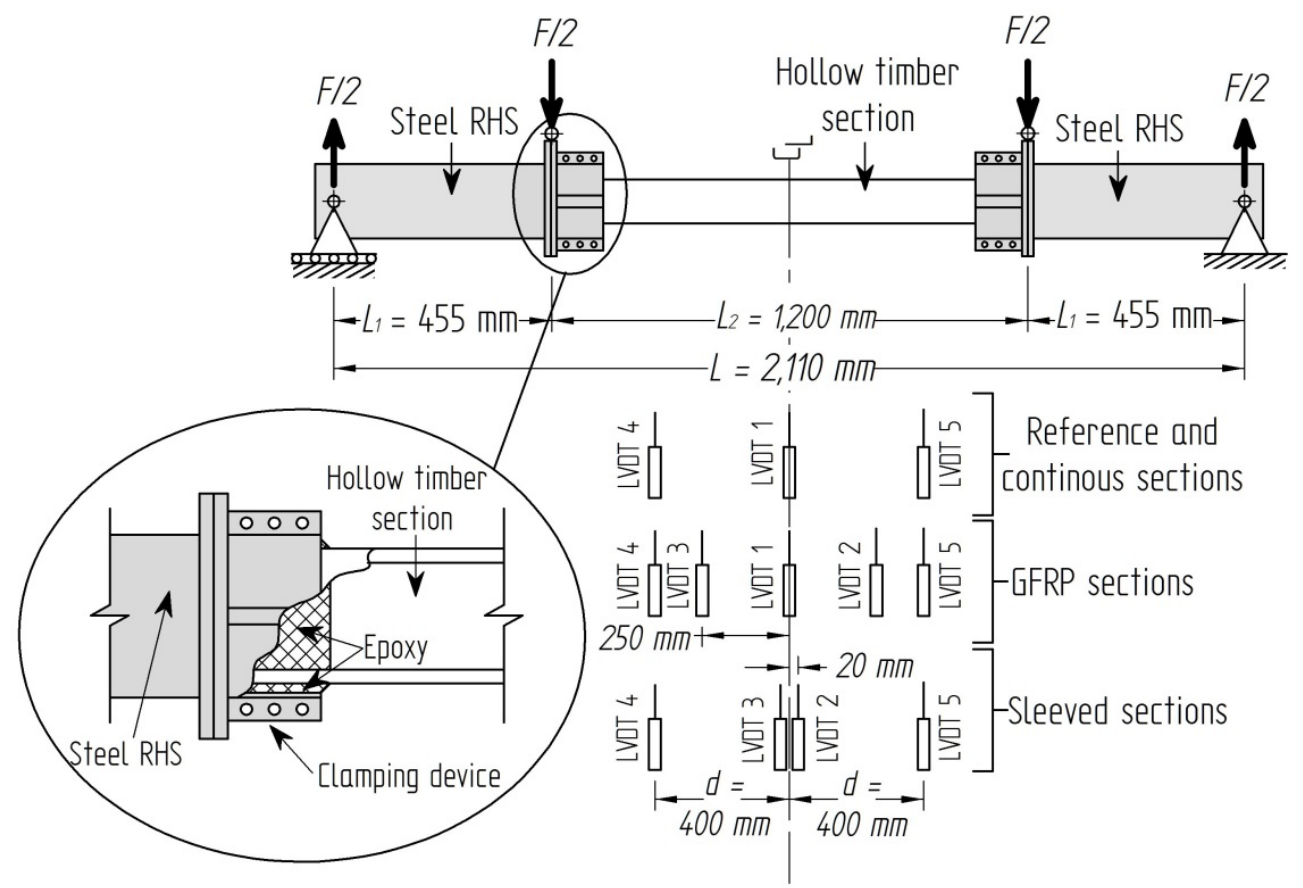

(a)

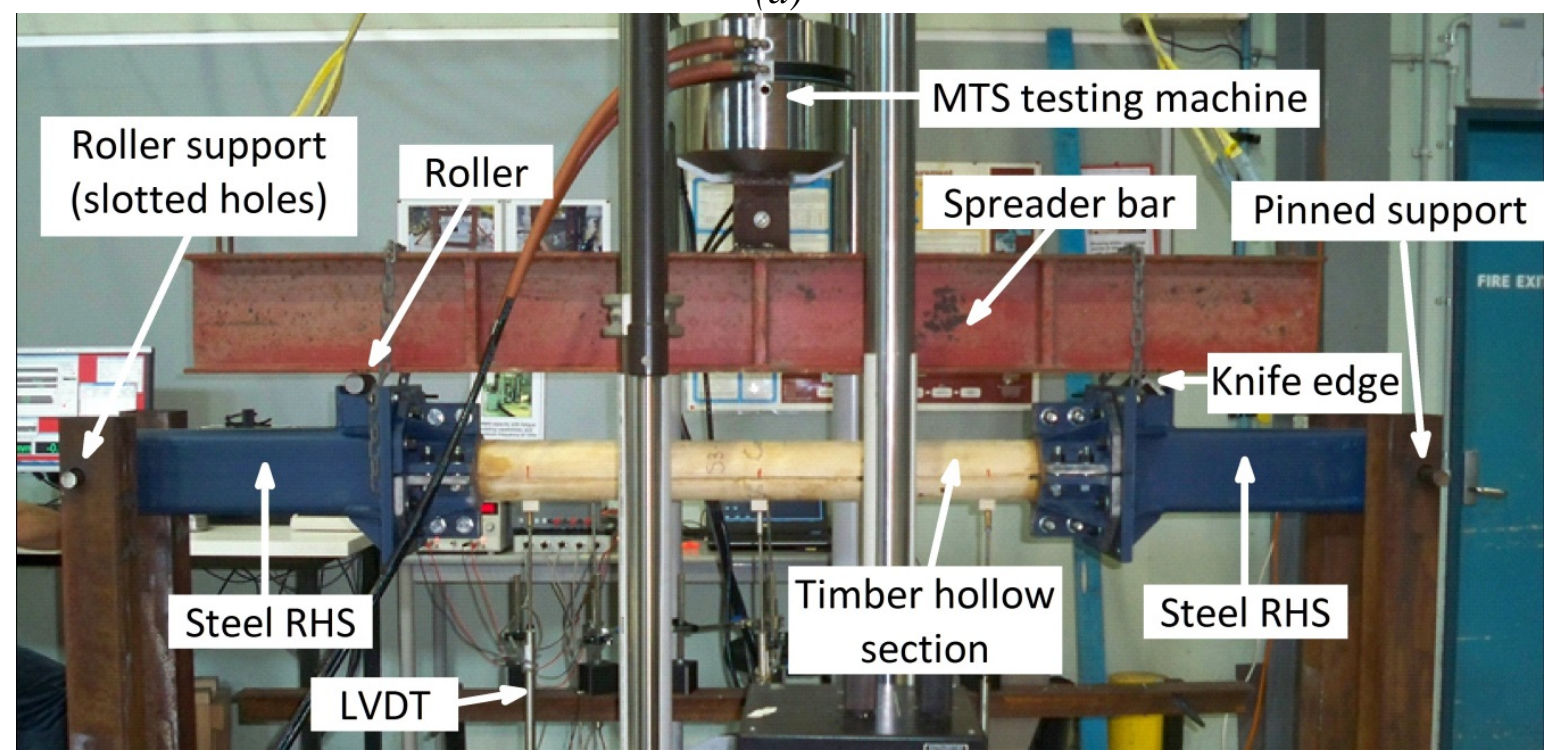

(b)

Figure 4: Test rig (a) Schematic and (b) Photo (shown for a reference section) 


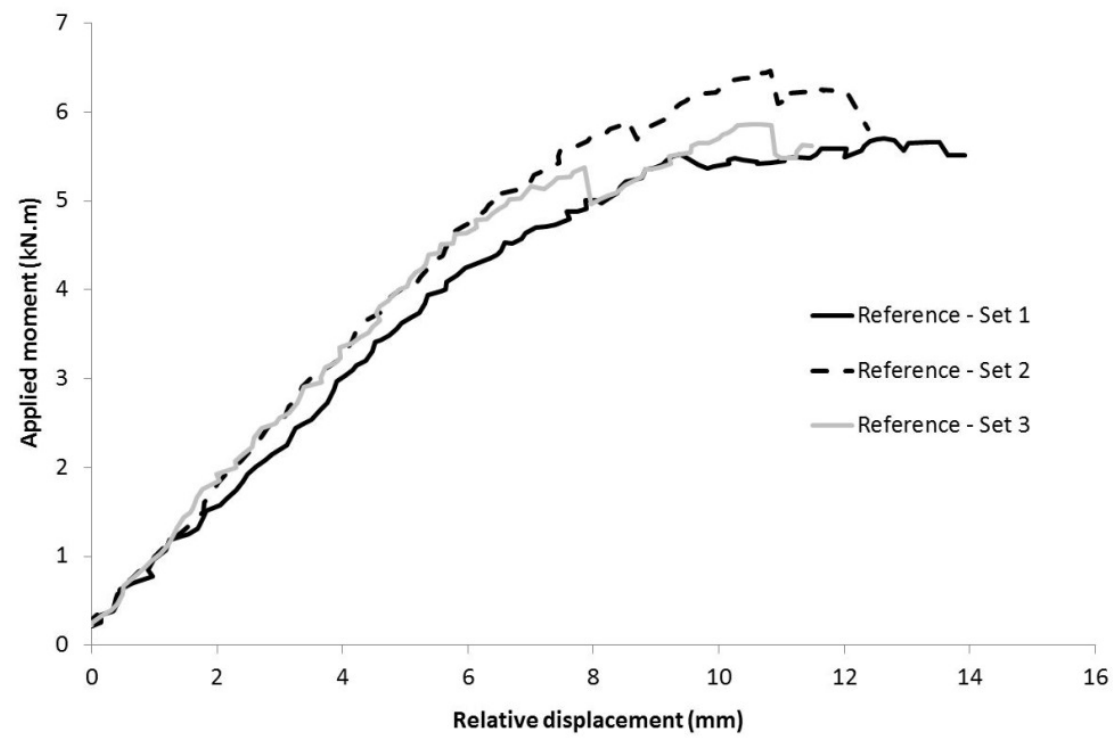

Figure 5: Moment-displacement curves of the reference sections

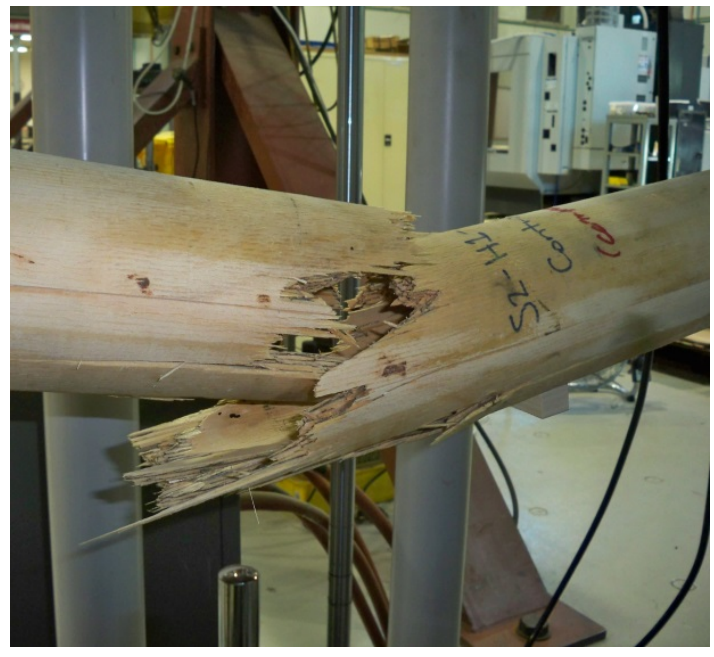

(a)

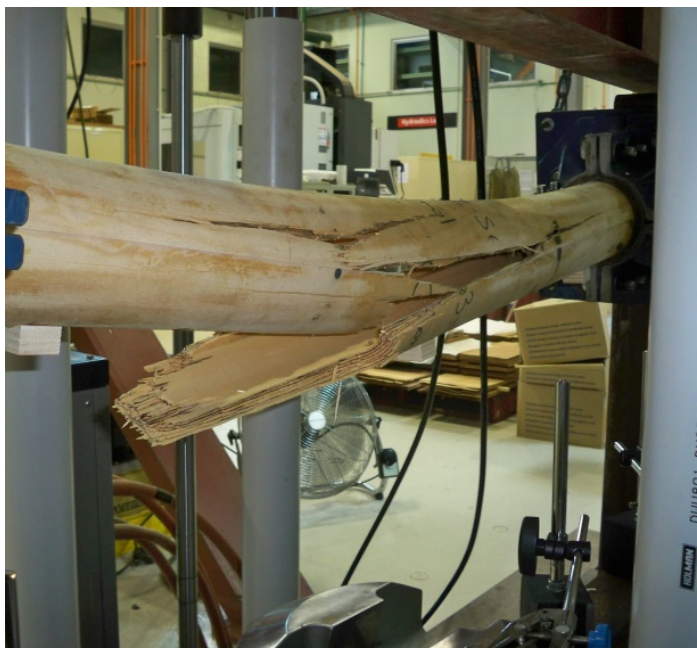

(b)

Figure 6: Brittle failure mode of the reference sections (a) Set 2 and (b) Set 3 


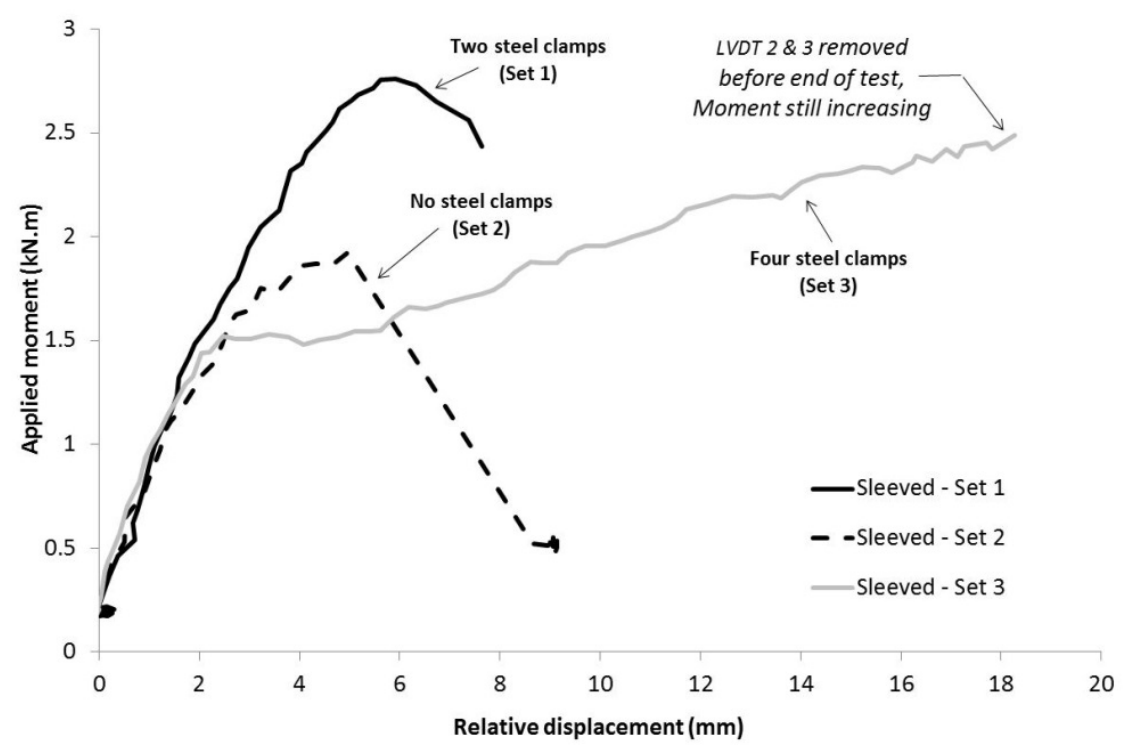

Figure 7: Moment-displacement curves of the sleeved sections (Concept 1)
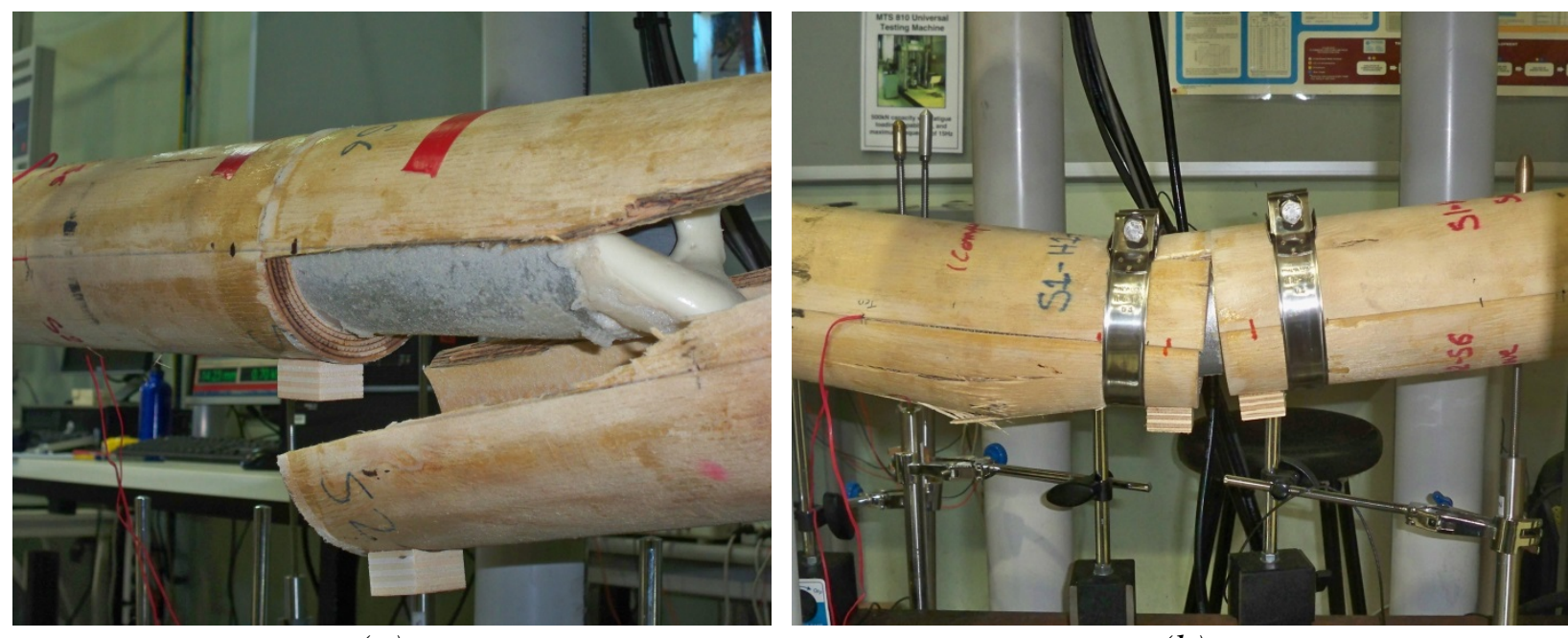

(a)

(b)

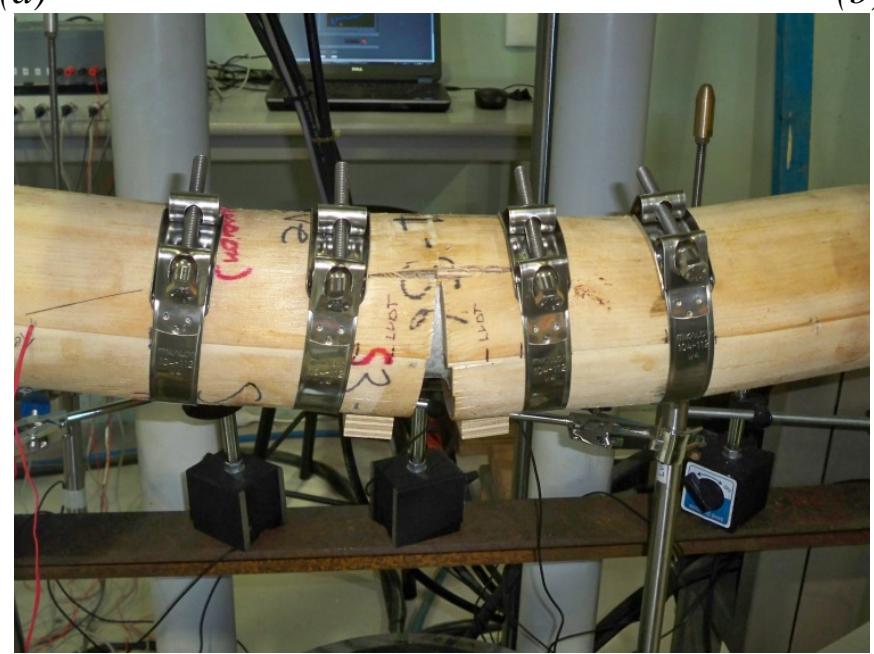

(c)

Figure 8: Failure modes of the sleeved sections (Concept 1) (a) Set 2 (no steel clamps), (b) Set 1 (two steel clamps) and (c) Set 3 (four steel clamps) 


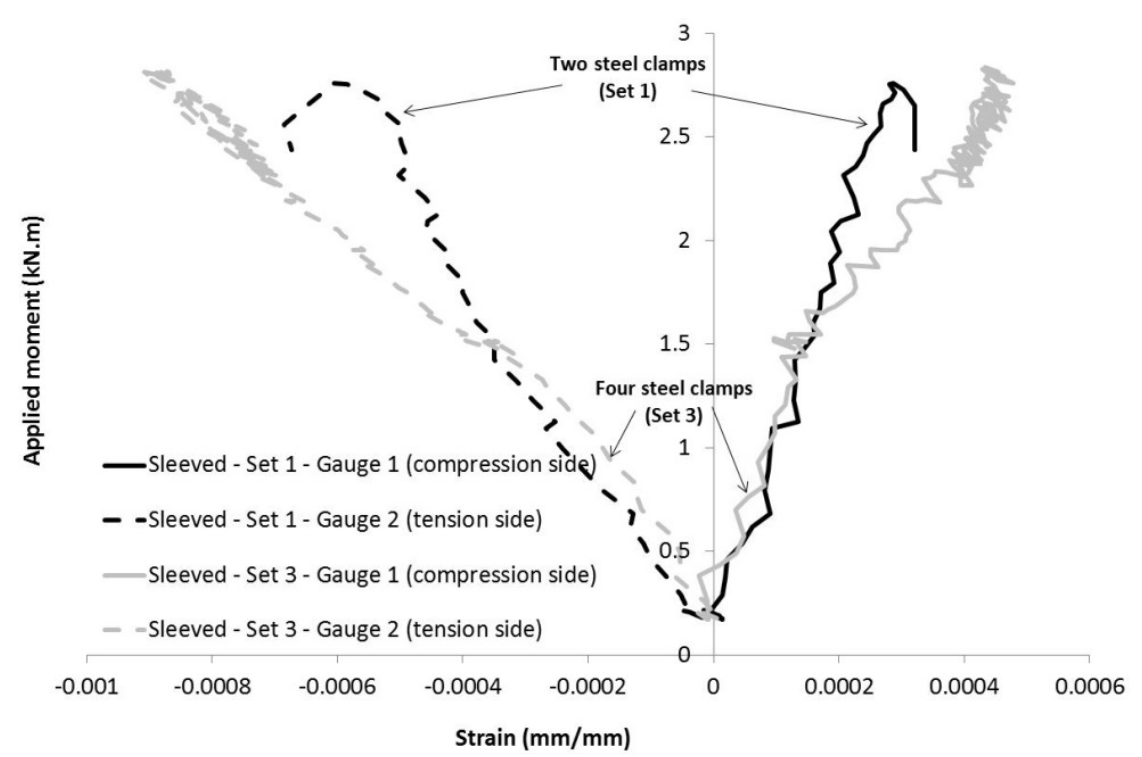

Figure 9: Aluminium sleeve strain gauge readings

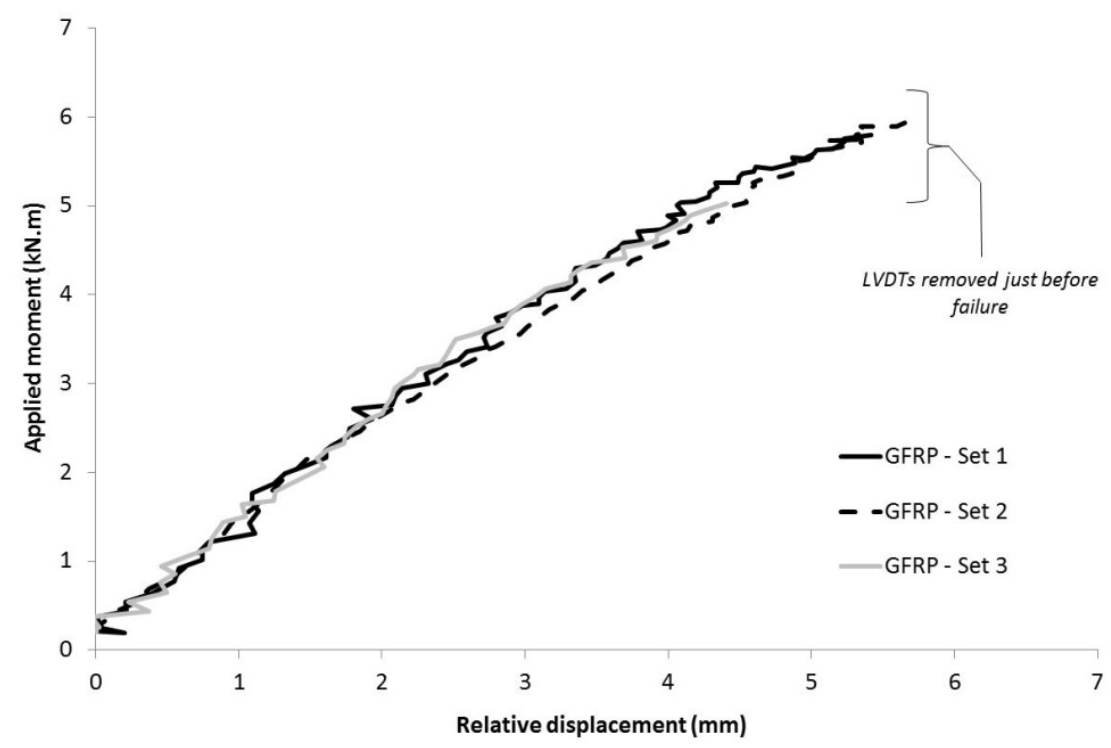

Figure 10: Moment-displacement curves of the FRP sections (Concept 2) 


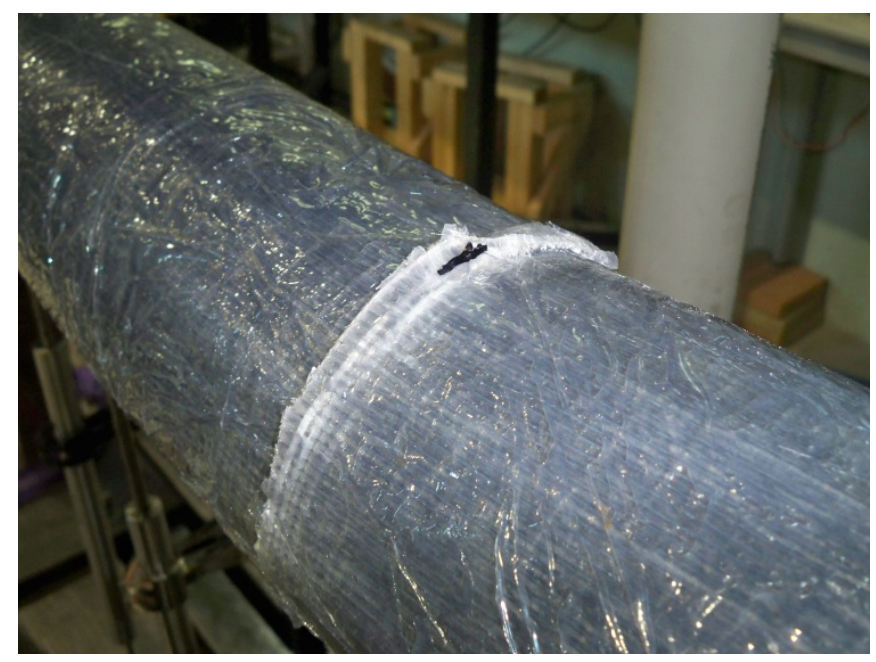

Figure 11: Typical failure mode of the FRP sections (Concept 2) in the compression zone, shown for Set 2

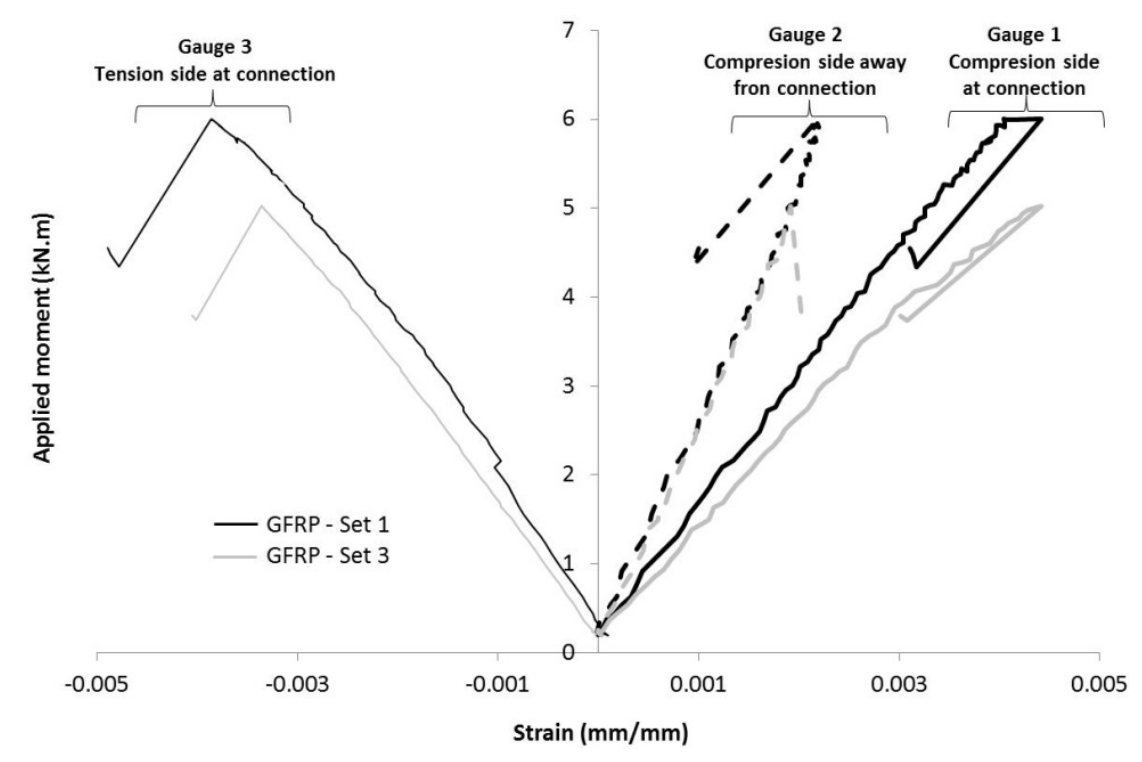

Figure 12: GFRP strain gauge readings 


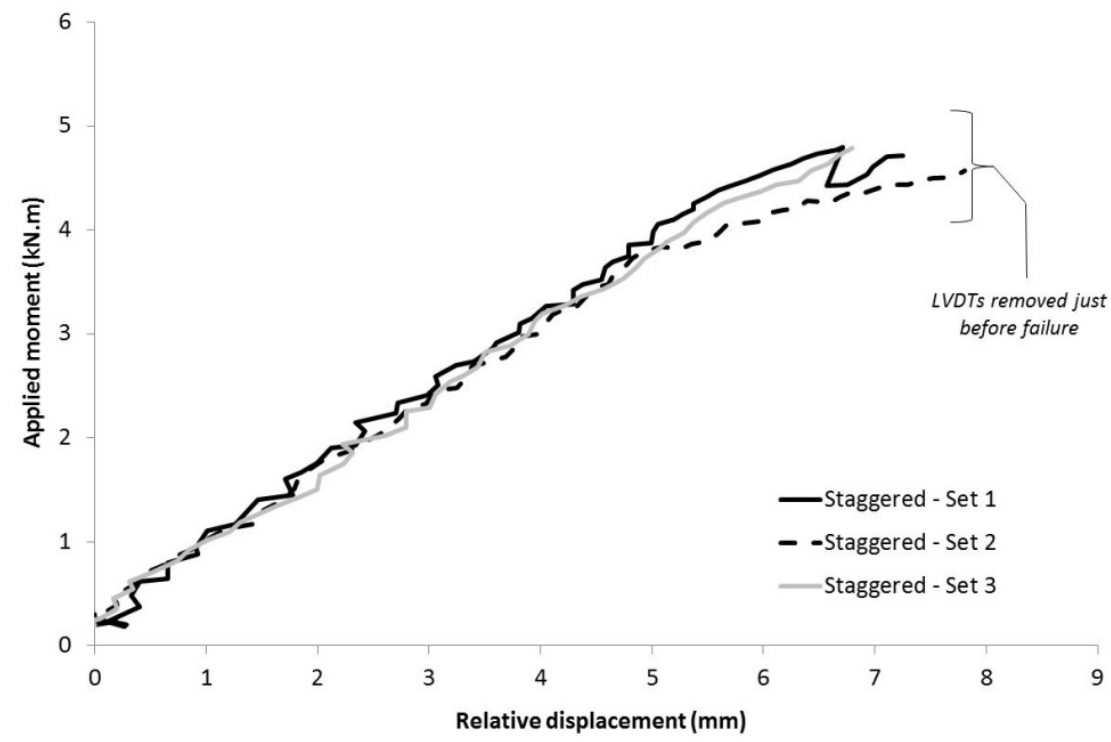

Figure 13: Moment-displacement curves of the continuous sections (Concept 3)

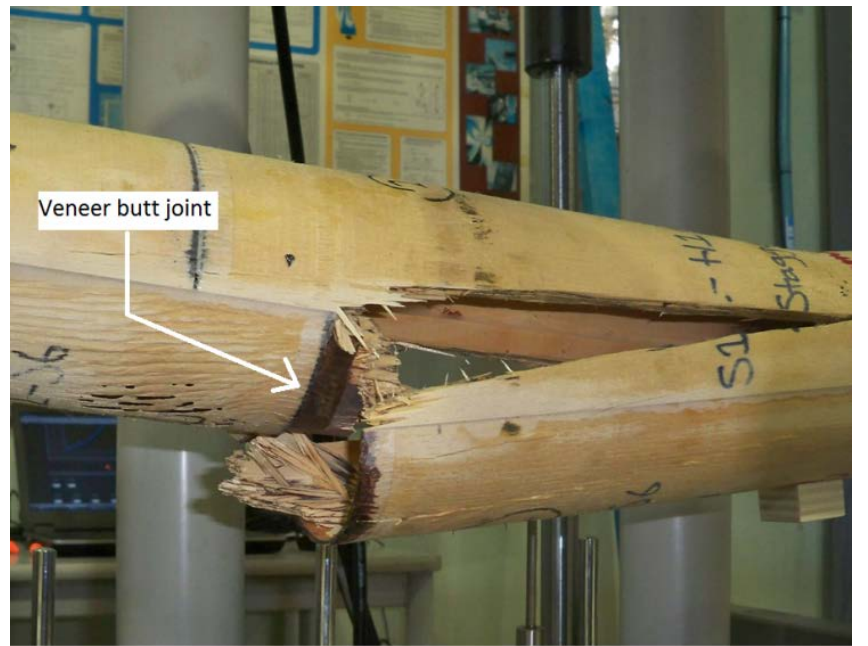

(a)

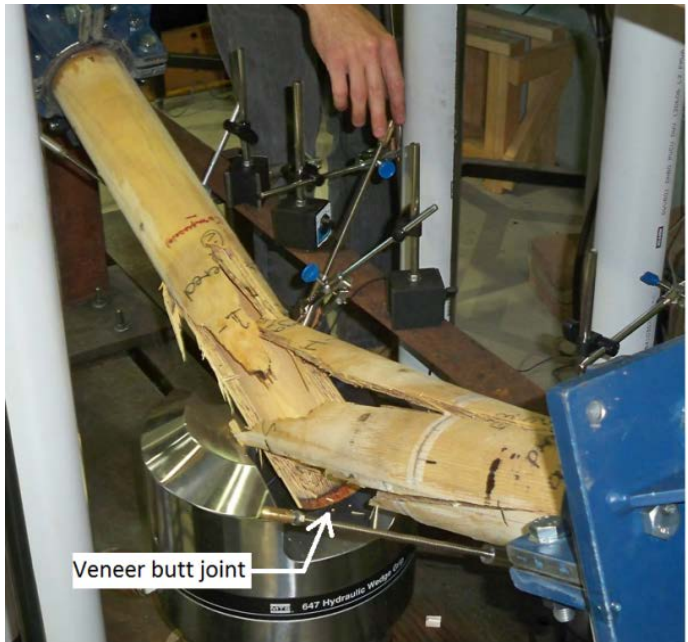

(b)

Figure 14: Failure mode of the continuous sections (Concept 3), (a) Set 1 and (b) Set 3 


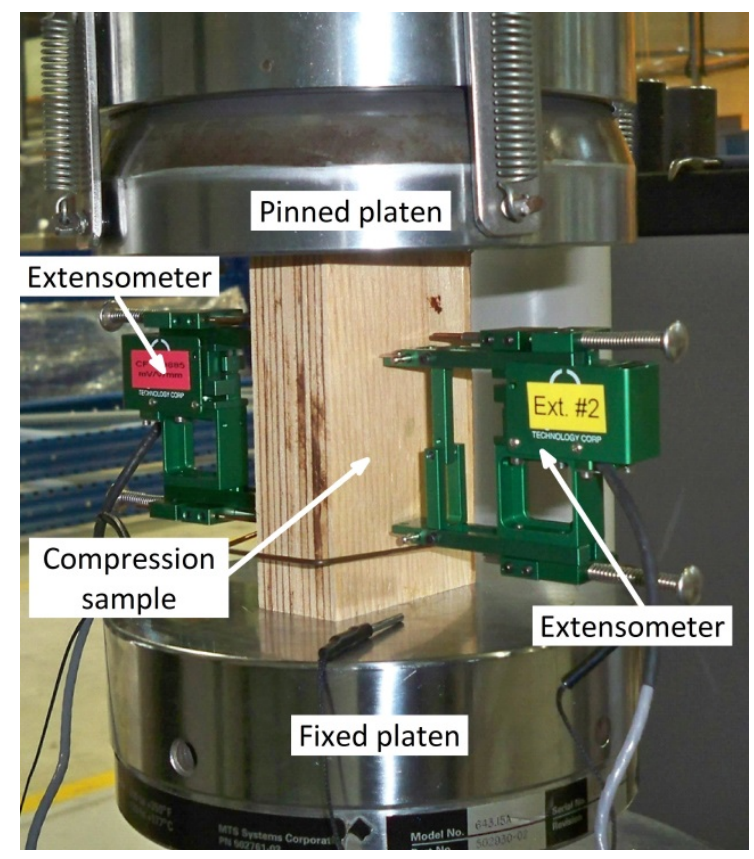

(a)

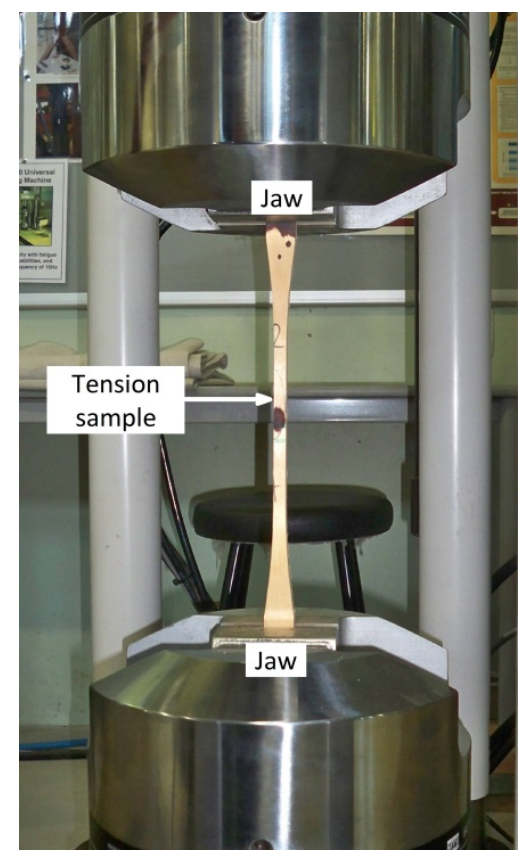

(b)

Figure 15: Material testing, (a) Compression and (b) tension test set-ups 
Table 1: Bending capacity of the tested sections and numerical model results

\begin{tabular}{c|c|ccc|cc}
\hline \multirow{2}{*}{ Set } & $\begin{array}{c}\text { Reference section } \\
\text { bending capacity }\end{array}$ & \multicolumn{2}{|c|}{$\begin{array}{c}\text { Tested concept capacity to refer- } \\
\text { ence section capacity ratio }\end{array}$} & \multicolumn{2}{c}{$\begin{array}{c}\text { Numerical model capacity to } \\
\text { tested section capacity ratio }\end{array}$} \\
\cline { 3 - 7 } & $M_{s}(\mathrm{kN} . \mathrm{m})$ & Sleeve & FRP & Continuous & Reference & Continuous \\
\hline 1 & 5.72 & $0.48^{(2)}$ & 1.05 & 0.95 & 0.97 & 0.90 \\
2 & 6.47 & $0.30^{(1)}$ & 0.93 & 0.73 & 0.97 & 1.15 \\
3 & 5.90 & $0.49^{(3)}$ & 0.85 & 0.81 & 1.07 & 1.14 \\
\hline Average & 6.03 & 0.42 & 0.94 & 0.83 & 1.00 & 1.06 \\
CoV $(\%)$ & 6.43 & 25.38 & 10.56 & 13.44 & 5.90 & 13.05 \\
\hline
\end{tabular}

${ }^{(1)}$ No steel clamps; ${ }^{(2)}$ Two steel clamps; ${ }^{(3)}$ Four steel clamps

Table 2: Bending stiffness of the reference sections

\begin{tabular}{c|c|c}
\hline Set & Bending stiffness $E_{s} I_{s}\left(\mathrm{kN} . \mathrm{mm}^{2}\right)$ & Measured second moment of area $I_{s}\left(\mathrm{~mm}^{4}\right)$ \\
\hline 1 & $5.56 \times 10^{7}$ & $4.771 \times 10^{6}$ \\
2 & $6.32 \times 10^{7}$ & $4.910 \times 10^{6}$ \\
3 & $5.84 \times 10^{7}$ & $4.863 \times 10^{6}$ \\
\hline
\end{tabular}

Table 3: Material testing - Strength

\begin{tabular}{c|ccc|ccc}
\hline \multirow{2}{*}{ Set } & \multicolumn{3}{|c|}{ Half-section in compression } & \multicolumn{3}{c}{ Half-section in tension } \\
\cline { 2 - 7 } & $\sigma_{f, \text { comp }}(\mathrm{MPa})$ & CoV $(\%)$ & Nb of tests & $\sigma_{f, \text { tens }}(\mathrm{MPa})$ & CoV (\%) & Nb of tests \\
\hline 1 & 44.7 & 1.99 & 4 & 65.0 & 9.70 & 4 \\
2 & 41.9 & 1.22 & 4 & 84.8 & 4.74 & 5 \\
3 & 45.0 & 0.83 & 4 & 80.2 & 9.14 & 3 \\
\hline
\end{tabular}

Table 4: Material testing - MOE

\begin{tabular}{c|ccc|ccc|ccc}
\hline & \multicolumn{6}{|c|}{ Half-section in compression } & \multicolumn{3}{c}{ Half-section in tension } \\
\hline & \multicolumn{3}{|c}{ Extensometer } & \multicolumn{3}{c|}{ BING } & \multicolumn{3}{c}{ BING } \\
\cline { 2 - 10 } Set & MOE & CoV & Nb of & MOE & & Nb of & MOE & CoV & Nb of \\
$(\mathrm{MPa})$ & $(\%)$ & tests & $(\mathrm{MPa})$ & $\mathrm{CoV}$ & tests & $(\mathrm{MPa})$ & $(\%)$ & tests \\
\hline 1 & 14,897 & 7.60 & 4 & 15,647 & 0.09 & 2 & 14,897 & 1.42 & 2 \\
2 & 12,335 & 3.50 & 3 & 13,490 & 4.53 & 2 & 15,523 & 6.82 & 2 \\
3 & 13,616 & 3.15 & 3 & 15,602 & 3.97 & 2 & 15,440 & 1.35 & 2 \\
\hline
\end{tabular}

